\title{
Removing of hydrocarbon contaminated soil via air flushing enhanced by surfactant
}

\author{
Th. Abdel-Moghny $\cdot$ Ramadan S. A. Mohamed • \\ E. El-Sayed • Shoukry Mohammed Aly • \\ Moustafa Gamal Snousy
}

Received: 2 August 2011/Accepted: 27 June 2012/Published online: 2 August 2012

(C) The Author(s) 2012. This article is published with open access at Springerlink.com

\begin{abstract}
Surfactants enhanced air sparging actually acts to displace the organic contaminant entrapped in soil pores. In this work, a comparison study was carried out between two air-flushing modes, namely, continuous air flushing and pulsed air flushing, which was conducted to remediate soil contaminated with waste-lubricant oil. Therefore, coarse sand was artificially polluted and mixed well with waste-lubricant oil at different concentrations of 10,25 and $50 \mathrm{wt} \%$ to give the soil an oil blend. Then a laboratory glass column was established and backed with contaminated soil to study the effect of flow rate, pollutant and surfactant concentrations on the removal of waste-lubricant oil from soil. The contaminated soil was washed with pure water and flushed with both air-flushing modes at a pressure of $2 \mathrm{kPa}$ and flow rate of $6 \mathrm{~L} \mathrm{~min}^{-1}$. After that fixed $300 \mathrm{~mL}$ nonionic surfactant solutions $\left(\mathrm{NPEO}_{9.3}\right)$ at concentrations of 3, 5 and $7 \mathrm{wt} \%$, were poured individually along with air injection at the same pressure and flow rate. The treated soil was washed several times with pure water
\end{abstract}

\footnotetext{
Th. Abdel-Moghny ( $\square)$

Applications Department, Egyptian Petroleum Research Institute, Ahmed El-Zomer, Nasr City, Box. No. 11727, Cairo, Egypt

e-mail: thanaa_h@yahoo.com

R. S. A. Mohamed · E. El-Sayed - M. G. Snousy

Geology Department, Faculty of Science, El-Minia University, El-Minia, Egypt

e-mail: esamelsayed@yahoo.com

M. G. Snousy

e-mail: moustafa_gamal93@yahoo.com

S. M. Aly

Executive General Manager Collection and Treatment of Used Oil Petrotreat Co, Cairo, Egypt

e-mail: shokrymorsy@yahoo.com
}

to eliminate the residual surfactant solutions. It was found that water washing and air injection remove $27 \%$ of oil; however, air injection along with surfactant solutions increased the oil removal efficiency up to $90 \%$. Moreover, both air-flushing modes succeeded in removing the pollutant with majority to pulsed air mode over continuous mode; therefore, pulsed air flushing was applied for 25 and $50 \mathrm{wt} \%$ waste lubricant oils in presence of $3 \mathrm{wt} \%$ nonionic surfactant.

Keywords Air injection - Soil washing - Surfactant flushing · Waste-lubricant oils

\section{Introduction}

Somasundaran et al. [19] investigated the feasibility of using flotation process to remove non-volatile hydrophobic compounds (paraffin oil) from artificially contaminated soil (particle size $0.075-0.83 \mathrm{~mm}$ ) using sodium dodecyl sulfate (SDS). Their study indicated that soil washing through flotation with $0.1 \%$-mass SDS solution is effective in reducing the amount of oil in soil comparing with the ex situ soil washing method, which showed $50 \%$ less oil removal at concentration of $0.5 \%$-mass. Limited literature has shown that significant amount of petroleum oil may be removed from contaminated soil by flotation process $[2$, $19,23,25]$.

Soil contamination with spillage lubricant oils generally results from leaking underground storage tanks, pipelines and accidental spills [4, 16]. Air-flushing technique involves introducing forced air into the artificially contaminated soil to encourage removal of contaminants. Air flushing is a cost-effective, time-efficient system for the remediation of volatile organic compounds (VOCs), 
particularly dissolved petroleum hydrocarbon and/or biodegradable contaminants [14, 15, 18]. Two mechanisms suggested for air flushing to reduce the dissolved organic compounds in subsurface area: (1) physical stripping (volatilization) as air moves through the aquifer and (2) aerobic biodegradation of VOCs through increased oxygen supply [7].

Surfactants enhance organic contaminant act by two mechanisms. First, surfactants reduce the interfacial tension between water and contaminants that slow the mobility of the organic components, thereby, surfactants can be able to transfer the hydrophobic organic compounds (HOCs) to the mobile phase [1]. Secondly, surfactants are capable of forming aggregates known as micelles, thus solubilizing HOCs. Numerous studies have indicated that surfactants can enhance recoveries of non-aqueous phase liquids [6, 17].

Urum et al. [22], study removal of crude oil from soil using air flushing assisted stirred tank reactors. Two surfactants (rhamnolipid and SDS) were tested and the effects of different parameters (i.e., temperature, surfactant concentrations, washing time, volume/mass ratio) were investigated under varying washing modes namely, stirring only, air flushing only and the combination of stirring and air flushing.

Surfactant-enhanced air flushing was conducted to remove perchloroethene (PCE) sources from laboratory flow chambers packed with sand. The resident water was supplemented with an anionic surfactant, (SDBS), to reduce the water's surface tension, and then sparged with nitrogen gas at a constant flow rate of $0.12 \mathrm{~min}^{-1}[9,10]$.

The present work aimed to applying air flushing as remedial technology for removing the waste-lubricant oil from soil in presence of nonionic surfactant polyethylene glycol nonylphenyl ether $\left(\mathrm{NPEO}_{9.3}\right)$. In this respect three different concentrations (3, 5 and wt $7 \%$ ) poured individually into laboratory glass column packed with contaminated sand. Two air injection modes continuous (direct injection) and pulsed (on/off interval mode) were applied and the effect of surfactant, pollutant concentrations, washing time and pressure had been studied. The results discussed based on application of surfactant enhancing air flushing techniques as the most suitable and cheapest remedial technology for removal of oil polluted soil.

\section{Materials and methods}

Materials

1. Coarse sand with diameter range from 0.5 to $1 \mathrm{~mm}$ with porosity equal $25 \%$ was used as porous medium.
2. Commercial grade nonionic surfactant polyethylene glycol nonylphenyl ether $\left(\mathrm{NPEO}_{9.3}\right)$ was purchased from Egyptian market and used as received, and its physical properties are given in as following; number of moles E.O is 9.3, HLB is 13.0, average molecular weight is $629.37 \mathrm{~g} \mathrm{~mol}^{-1}$, surface tension, dynes $/ \mathrm{cm}$ $\left(0.01 \%\right.$ aq., $\left.25^{\circ} \mathrm{C}\right)$ is 32 , specific gravity, $\mathrm{g} \mathrm{ml}^{-1}$ is $1.05-1.07$, and its biodegradability is 90 .

3. Waste-lubricant oils were collected from different factories and companies and were used as pollutant. The physical properties of the used lubricating oils are as the following, the specific gravity at $20^{\circ} \mathrm{C}$ is 0.875 , flash point (close cup Pensesky Martin) is $140{ }^{\circ} \mathrm{C}$, water and sediment is 1.28 ( $\mathrm{vol} \%)$, water content [Dean and Stark method is 0.79 (vol\%)], Viscosity at $37.8^{\circ} \mathrm{C}$ is $209.235 \mathrm{cst}$, ash content is $0.714 \mathrm{wt} \%$, asphaltene content is $4.995 \mathrm{wt} \%$.

4. n-Hexane supplied by Aldrich Chemical Co. and used without further treatment.

\section{Determination of surface tensions and CMC}

Surface tensions of surfactant solutions were determined with Wilhelmy plate Krüss K100 Tensiometer instrument that operates based on DuNouy principle. The critical micelle concentration (CMC) was determined by measuring the surface tension versus surfactant concentration.

\section{Solubilization of lubricant oils in surfactant solutions}

The ability of surfactant solutions to solubilize the wastelubricant oil was investigated by mixing $30 \mathrm{ml}$ surfactant solutions at concentrations ranging from 0.01 to $0.05 \%$ with $0.5 \mathrm{ml}$ waste-lubricant oils. Then the solutions were continuously shaken at $25^{\circ} \mathrm{C}$ for $48 \mathrm{~h}$. The sample vials were allowed to settle at $24 \mathrm{~h}$ for phase separation. After that, the aqueous phase was withdrawn and extracted with chloroform to determine the concentration of solubilized lubricant oil using ultraviolet spectroscopy.

Soil contamination

According to Urum et al. [21], a fixed mass of $1 \mathrm{~kg}$ of coarse sand $(0.5-1 \mathrm{~mm})$ was artificially polluted and mixed well with waste-lubricant oils at different concentrations of 10,25 and $50 \mathrm{wt} \%$, to give soil oil blend.

Experimental set-up and procedure

As shown in Fig. 1, a cylindrical Plexiglas column having dimension $(105 \times 5 \times 4.5 \mathrm{~cm})$, was packed with $31 \mathrm{~cm}$ height of $10 \mathrm{wt} \%$ contaminated sandy soil. The outlet end 
Fig. 1 The laboratory experimental model

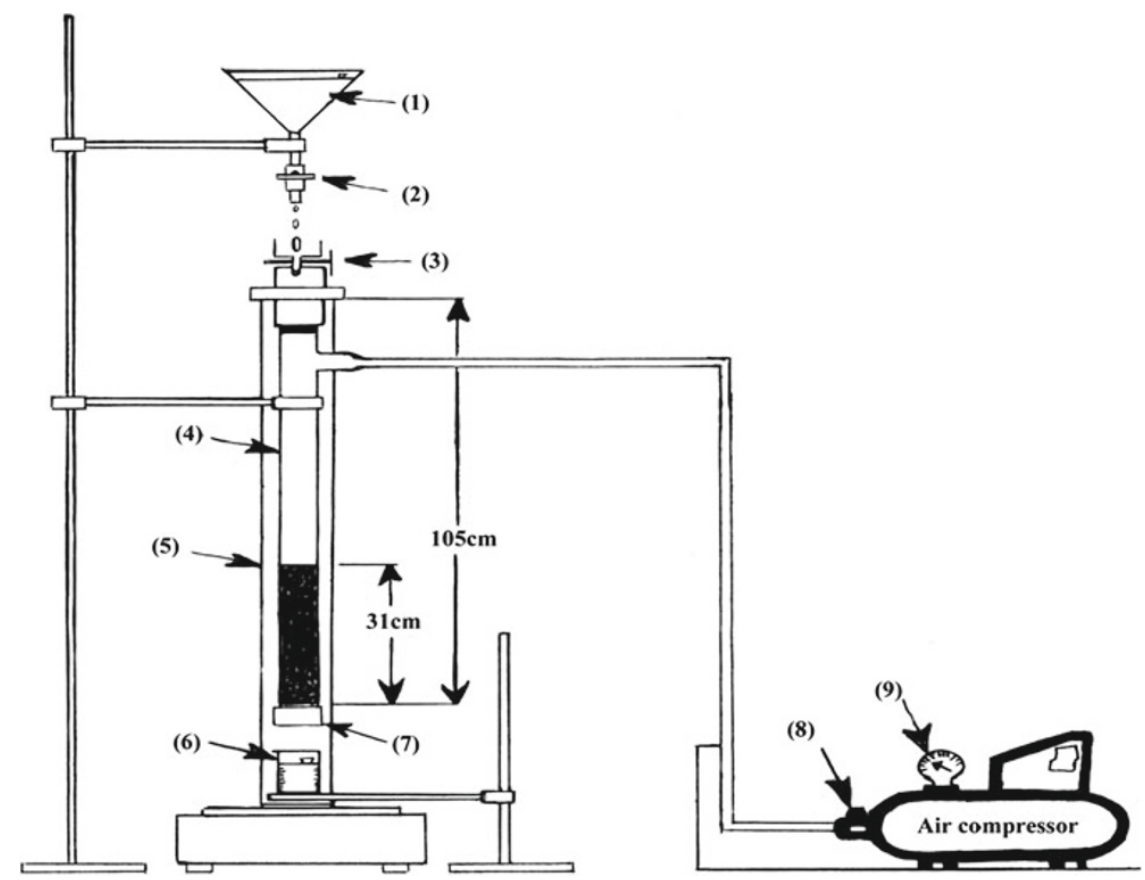

(1) Washing solutions, (2) Valve, (3) Input column valve, (4) Column, (5) Column support, (6) Effluent beaker, (7) Wire mesh, (8) On/off control button, (9) Gauge. of the column was fitted with a fine wire mesh screens (50 $\mu \mathrm{m}$ diameter) to prevent soil wash out. The column was cautiously packed with coarse sand (diameter range $0.5-1 \mathrm{~mm}$ ) to insure better distribution of injected air during air flushing and preventing the sand particles from clogging the orifice where air was introduced. Then the column was filled with nonionic surfactant solutions $\left(\mathrm{NPEO}_{9.3}\right)$, prior to packing sand to avoid air bubble entrapment. Two air injection modes were applied in this study, the first one is continuous (direct injection), the second is pulsed (on/off interval mode), both modes are carry out to increasing contaminant mass removal. Air was injected at the side arm of the column into the coarse sand saturated with surfactant solution using opening air compressor system, as described by Kommalapati [11] Air delivery was controlled with a low-pressure regulator and flow meter. The flow rates ranged between $6 \mathrm{~L} \mathrm{~min}^{-1}$. The air inlet stream was directed to create turbulent air current and to provide better distribution of the injected air with similar and strong focusing at all points of soil surface. The procedure used for soil packing was reproduced with 25 and $50 \mathrm{wt} \%$ contaminated sandy soil without substantial variation in the characteristics of the packed soil.

Soil remediation by surfactant flushing

The experiment was conducted to study the pollutant removal with nonionic surfactant solutions, and then study the effect of water washing cycles for eliminate the residual oil entrapped in soil. In this respect, a fixed $300 \mathrm{~mL}$ of $\left(\mathrm{NPEO}_{9.3}\right)$ at 3, 5 and $7 \mathrm{wt} \%$ concentrations were poured into cylindrical plexiglas column containing $10 \%$ contaminated soil. Then a compressed air at a pressure of 2 bar $\left(2 \mathrm{~kg} / \mathrm{cm}^{2}\right)$ and flow rate $6 \mathrm{~L} \mathrm{~min}^{-1}$ was introduced through the side arm of the column. The pressure was monitored using a pressure gauge as shown in Fig. 1. All experiments were carried out at $25 \pm 1{ }^{\circ} \mathrm{C}$. Experiments were also conducted in downflow (gravity-stable). During the downflow flushing experiments, surfactant solutions were poured individually into the top, and the oily waste was recovered from the bottom of the soil column. To rinse off the washed soil, the remaining waste oil was improved by different water cycles. Then the effluent was collected in $50 \mathrm{ml}$ centrifuge tubes, for both surfactant and water runs, and the oil remaining in soil was determined.

Analysis of effluent oily waste

The collected effluent distinct into two phases: oil phase and an aqueous phase. The oil phase was recovered by centrifuging the effluent at 10,000 rpm for $10 \mathrm{~min}$ and the supernatant aqueous phase was pipette out. The soil and oily waste mixture was separated and weighted. Finally, the oils remaining in soil was extracted by shaken laterally $1 \mathrm{~g}$ of soil for $5 \mathrm{~min}$ with $10 \mathrm{~cm}^{3}$ of $n$-hexane, the washing with $n$-hexane was continued until nearly all the oily waste 
was removed from the soil. The $n$-hexane/oils extract was collected into one volumetric flask up to $50 \mathrm{~cm}^{3}$ with $n$ hexane and oil percentage was determined using ultra violet spectroscopy.

\section{Determination of oil removing percentage}

The oils removed from soil using single air flushing in absence and presence of surfactant was determined and the results are given in Tables 1 and 4 .

\section{Results and discussion}

Waste-lubricant oils includes crankcase (engine) oil, brake fluid, automatic transmission fluid, power steering fluid, liquid and semi-solid gear, chain, and ball bearing lubricants, and hydraulic fluid. Waste-lubricant oils are not considered hazardous waste unless it is mixed with a hazardous waste such as a chlorinated solvent. The problem of soil and groundwater pollution was widely recognized in recent years. The flushing air creates air bubbles where the oil will adhere.

\section{Surface tension and CMC of surfactant}

The surface tension of nonionic surfactant solutions was determined using $0.01 \%$ of (polyethylene glycol nonylphenyl ether) in pure distille water @ $25{ }^{\circ} \mathrm{C}$. It is found that the surface tension of surfactant solutions is $32 \mathrm{~m} \mathrm{~N} \mathrm{~m}^{-1}$, and its CMC have spans between 0.13 and $0.2 \mathrm{~g} \mathrm{~L}^{-1}$ or $\left(0.2-0.31 \mathrm{mmol} \mathrm{L}^{-1}\right)$.

\section{Apparent solubility}

The surfactant concentrations used in current study were $3 \%, 5 \%$ and $7 \mathrm{wt} \%$, that equivalent to 15,25 and 35 times more than its CMC. It was found that the apparent wastelubricant oil solubility increased linearly with increasing surfactant concentrations above their CMC. The increased solubility may increase the potential removal of trapped waste-lubricant oil droplets. At low concentrations in aqueous solution, single molecules are present. The use of surfactants enhances the solubility of oil significantly by partitioning it into the hydrophobic cores of surfactant micelles. However, beyond a CMC, the surfactant molecules will aggregate, form micelles and reduce the thermodynamic energy in the system. Thereby, surfactants act to reduce the free energy of the system by replacing the bulk molecules of higher energy at an interface.

Air flushing technology and its application

With stress emphasis on air injection mode its recognized that there are two air injection mode well-known, the first one is continuous (direct injection), the second is pulsed (on/off interval mode), both modes are carry out to increasing contaminant mass removal.

\section{Effect of continuous air flushing on removed oil}

The compressed air has been injected into the saturated sand column by opening air compressor as illustrated in Fig. 1; in this respect, $1 \mathrm{~kg}$ of coarse sand contaminated with $10 \%$ waste oil was subjected to applying continuous air flushing via separate two steps as the following: (1) flushing the contaminated soil with air only for $2,700 \mathrm{~s}$ as a blank, (2) flushing the contaminated soil with different surfactant solutions enhanced with air injection followed by washing several times with pure water to eliminate the residual surfactant solutions. The removal rate of $10 \mathrm{wt} \%$ waste lubricant oils using continuous air injection was given in Table 1. The results showed that the quantities of waste oil repel out from soil due to action of air flushing only is $27 \mathrm{wt} \%$, and the consuming time during such process is $2,700 \mathrm{~s}$. The flushing time applying and selected depending on no effluent was passing. After that the action of surfactant solutions enhanced with air injection were apply on the same model and the results are recorded in Table 2. The results revealed that the values of removed oil are raised up to $93 \%, 96 \%$, and $97 \mathrm{wt} \%$ after flushing with $3 \%, 5 \%$ and 7 wt $\%$ surfactant solutions at 600,200 , and $90 \mathrm{~s}$, respectively. This can be explained by, during injection of air flushing enhanced by surfactant solutions, the waste lubricant oils entrapped in soil pores were migrate because the interfacial tension between waste lubricant oils and the surfactant solution became low enough to force the blobs or ganglia of waste lubricant oils to move away. Sequentially, it can rapidly remove a large fraction of pollutant mass entrapped in the soil. It is also

Table 1 Removed oil \% @ $10 \mathrm{wt} \%$ polluted soil using continuous air flushing

\begin{tabular}{llll}
\hline Condition & $\begin{array}{l}C_{i}(\mathrm{mg} / \mathrm{g}) \text { is the initial soil } \\
\text { concentration of pollutant }\end{array}$ & $\begin{array}{l}C_{A}(\mathrm{mg} / \mathrm{g}) \text { is the final soil concentration } \\
\text { of pollutant after air injection. }\end{array}$ & Removed oil $\%=\frac{\left(C_{i}-C_{A}\right)}{\left(C_{i}\right)} \times 100$ \\
\hline $\begin{array}{l}\text { After injection } \\
\text { for } 45 \mathrm{~min}\end{array}$ & 0.0001 & $7.29 \mathrm{E}^{-05}$ & 27 \\
\hline
\end{tabular}


Table 2 Removed oil \% @ 10 wt\% polluted soil using continuous air flushing with pollutant, different surfactant solution, and water

\begin{tabular}{|c|c|c|c|c|c|c|c|c|c|c|}
\hline \multirow[t]{2}{*}{$\begin{array}{l}\text { Air pulsing } \\
\text { No. }\end{array}$} & \multicolumn{2}{|c|}{$\begin{array}{l}\text { Air flushing and } \\
\text { pollutant (blank) }\end{array}$} & \multicolumn{2}{|c|}{$\begin{array}{l}\text { Air flushing, pollutant } \\
\text { and } 3 \% \text { surfactant } \\
\text { (NPEox) }\end{array}$} & \multicolumn{2}{|c|}{$\begin{array}{l}\text { Air flushing, pollutant } \\
\text { and and } 5 \% \text { surfactant } \\
\text { (NPEox) }\end{array}$} & \multicolumn{2}{|c|}{$\begin{array}{l}\text { Air flushing, pollutant } \\
\text { and } 7 \% \text { surfactant } \\
\text { (NPEox) }\end{array}$} & \multicolumn{2}{|c|}{$\begin{array}{l}\text { Air flushing, pollutant, } \\
\text { and water }\end{array}$} \\
\hline & $\begin{array}{l}\text { Flushing } \\
\text { time (s) }\end{array}$ & $\begin{array}{l}\% \text { of removed } \\
\text { oil }\end{array}$ & $\begin{array}{l}\text { Flushing } \\
\text { time (s) }\end{array}$ & $\begin{array}{l}\% \text { of removed } \\
\text { oil }\end{array}$ & $\begin{array}{l}\text { Flushing } \\
\text { time }(\mathrm{s})\end{array}$ & $\begin{array}{l}\% \text { of removed } \\
\text { oil }\end{array}$ & $\begin{array}{l}\text { Flushing } \\
\text { time }(\mathrm{s})\end{array}$ & $\begin{array}{l}\% \text { of removed } \\
\text { oil }\end{array}$ & $\begin{array}{l}\text { Flushing } \\
\text { time (s) }\end{array}$ & $\begin{array}{l}\% \text { of removed } \\
\text { oil }\end{array}$ \\
\hline First & 2,700 & 27 & 600 & 93 & 200 & 96 & 90 & 97 & 30 & 30 \\
\hline Second & & & 78 & 94 & 35 & 95 & 16 & 98 & & \\
\hline Third & & & 54 & 96 & 18 & 97 & 13 & 98 & & \\
\hline Fourth & & & 30 & 97 & 12 & 98 & 12 & 99 & & \\
\hline
\end{tabular}

shown in Table 2, that the water washing cycles in presence of air injection are succeeded for removing the residual oil, this means that during water washing, the percentage of oil removing increased significantly, and then became nearly constant at the end of the process. Therefore, the use of water in the remediation of highly contaminated soil as polishing treatment solution was shown of great interest. Our results proved the performance of water in the remediation of hydrocarbon-contaminated soil as found by Fernandez et al. [3].

Effect of flushing time and surfactant concentrations on removed oil

Figure 2 exhibits the effect of continuous air flushing time for remediation $10 \%$ polluted soil in absence and presence of surfactant solutions, it is clear a linear relationship between removing oil with surfactant concentrations and inverse relationship with flushing time. This means that the efficiency of removed oil increases as the surfactant concentrations increased. The drastic decrease in time is attributed to decrees of pollutant concentration, which results from cleaning or opening of air channels due to increasing of surfactant concentrations from $3 \%$ to $7 \mathrm{wt} \%$.

Surfactant concentrations used in current study are above its CMC. A good relationship between surfactant concentrations and percentage of removing oil is shown in

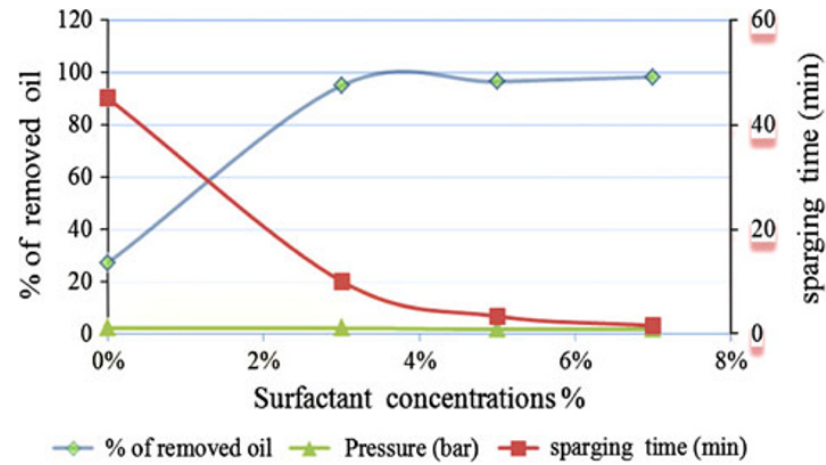

Fig. 2 Effect of continuous air flushing for remediation of $10 \%$ polluted soil in absence and presence of surfactant
Fig. 3. It is clear that the solubility of waste-lubricant oil being dependent on surfactant concentrations also surfactants reduce the interfacial tension between water and contaminants that slows the mobility of the organic components. In addition, surfactants are capable of forming aggregates known as micelles, thus solubilizing wastelubricant oil. Therefore, in order to overcome the difficulty of removal of non-volatile constituents like lubricating oil, the author advise by adding nonionic surfactant solution to enhance its recovery by solubility or desorption and subsequently accelerate the solubilization of the contaminated soil in presence of air flushing.

Effect of pulsing air flushing and time on removed oil

In this part the treatment of contaminated soil with different concentration $10 \%, 25 \%$ and $50 \mathrm{wt} \%(100,250$ and $500 \mathrm{~g} / \mathrm{kg}$ ) was carried out by pulsing air flushing in presence of surfactant solution followed by six water washing cycles. This step was performed at $(28.37 \mathrm{cf} / \mathrm{min})$ to evaluate the effectiveness of surfactant concentration versus different pollutant concentrations. The results of this treatment process are given in Table 3 . The results reveal that in the case of $10 \mathrm{wt} \%$ pollutant the removed oil are super grade and exceed to $93 \mathrm{wt} \%$ within $40 \mathrm{~s}$.

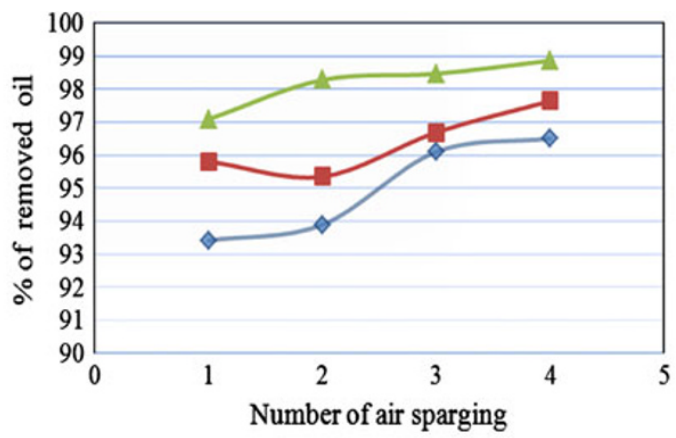

$\leftarrow \%$ of removed oil with $3 \%$ surfactant $\quad-\%$ of removed oil with $7 \%$ surfactant
$-\%$ of removed oil with $5 \%$ surfactant

Fig. 3 Effect of air flushing for remediation $10 \mathrm{wt} \%$ polluted soil in presence of different surfactant concentrations 
Table 3 Effect of time on removed oil $\% @ 10$ wt $\%$, and $25 \mathrm{wt} \%$ and $50 \mathrm{wt} \%$ polluted soil using pulsing air flushing @ 3 wt $\%$ surfactant

\begin{tabular}{|c|c|c|c|c|c|c|}
\hline \multirow[t]{2}{*}{ Air pulsing No. } & \multicolumn{2}{|c|}{$10 \mathrm{wt} \%$ contaminated soil } & \multicolumn{2}{|c|}{$25 \mathrm{wt} \%$ contaminated soil } & \multicolumn{2}{|c|}{$50 \mathrm{wt} \%$ contaminated soil } \\
\hline & $\%$ of removed oil & Flushing time (s) & $\%$ of removed oil & Flushing time (s) & $\%$ of removed oil & Flushing time (s) \\
\hline First & 93 & 40 & 63 & 173 & 11 & 2,700 \\
\hline Second & 94 & 26 & 69 & 30 & 7 & 2,100 \\
\hline Third & 97 & 20 & 77 & 29 & 7 & 2,000 \\
\hline Fourth & 98 & 19 & 82 & 26 & 7 & 1,970 \\
\hline Fifth & 99 & 19 & 84 & 23 & 7 & 1,970 \\
\hline Sixth & 99 & 19 & 86 & 22 & 6 & 1,964 \\
\hline Seventh & 99 & 19 & 91 & 19 & 3 & 1,962 \\
\hline
\end{tabular}

The injection of air sparging (by pulsed mode) in presence of 3 wt.\% surfactant help us to understand airflow pattern in the case of $10 \mathrm{wt} \%$ of pollutant concentration. Therefore, the movement and distribution of air through the aquifer in laboratory models have been studied to investigate airflow patterns in saturated soils at $25 \mathrm{wt} \%$ pollutant up to $50 \mathrm{wt} \%$.

In the case of $25 \%$ pollutant concentration Table 3, the efficiency of removed oil after first air flushing is $63 \mathrm{wt} \%$ and increased sharply tells to $91 \mathrm{wt} \%$ at seventh air flushing, this can attributed to air injection is temporarily turned off the water flows into the air channels and mixed with entrapped oil and formed emulsion. This mixing occurs in both microscale and macroscale air channels in sparging zones.

In the case of highly saturated soil up to $50 \mathrm{wt} \%$ pollutant concentration the date given in Table 3 reveals that, only $7 \mathrm{wt} \%$ of pollutant is removed under $2 \mathrm{kPa} @ 2,100 \mathrm{~s}$, after that the pressure was decreased and fixed at $1.5 \mathrm{kPa}$. This can attribute to that the oil exists as free phase. Free phase or mobile oil exists when the saturation is high enough to form pore-to-pore connections over a large area producing a continuous fluid. Furthermore, to recover the free phase of the waste lubricant oils in the treatment process it must be disposed of in accordance with applicable requirements. As well as it is necessary to use free-product recovery methods, which include each of vacuum or pumps to capture as much of the free flowing oil as possible.

The sum of all results illustrated that for a well-defined plume, a pump and treat system can be considered as an effective first line of defense in preventing further migration and in removing the bulk of free products. However, if the results of these studies are applied at relatively high airflow rates, the contaminant removal efficiency would be increased but the costs of air injection would also be significantly increased.

\section{Effect of pulsing air flushing on removed oil}

The treatment of contaminated soil was carried out using two steps: (1) injection by single air as marker, (2) washing with surfactant solution followed by washing with many water cycles. The removed oil using pulsing air injection is shown in Table 4.

The results reveal that in the case of the $10 \%$ pollutant, the percentage of oil removal is super grade and exceeded $96 \mathrm{wt} \%$; this means that the waste lubricant oil entrapped in soil pores migrated by the action of surfactant solution and forced the blobs or ganglia to move away.

In the case of the $25 \mathrm{wt} \%$ pollutant concentration the removed oil is nearly $79 \mathrm{wt} \%$; this means that the residual waste lubricant oil existing and entrapped in soil pores drained off leaving behind some amount of liquid trapped by capillary forces that holds a liquid to a solid surface.

In case of $50 \mathrm{wt} \%$ pollutant concentration the oil removed is not satisfactory and reached $7 \mathrm{wt} \%$ only, this can be attributed to the high degree of saturation, and the residual waste lubricant oil can exist as free phase or as mobile non-aqueous phase liquid. This means that the free phase of non-aqueous phase liquid exists when the saturation is high enough to form pore-to-pore connections over a large area, producing a continuous fluid capable of flowing under an imposed gradient or its own gravitational potential. Furthermore, to recover the free phase of the non-aqueous phase liquid in the treatment process unit it must be disposed of accordance with applicable requirements, as well as its necessary to use free-product recovery methods which include each of vacuum trucks or pumps to capture as much of the free-fluid oil as possible. Generally, to solve the problem of how to remediate the high pollutant concentration, first, it must be capture the free phase by mechanical treatment as first remediation defense, followed by chemical treatment.

The advantage of pulsed over continuous air flushing

In this section a comparison study was carried out between pulsed and continuous air flushing mode conducted for remediation of soil contaminated with lubricant oil. Such comparison was carried out to determine which air flushing mode will consumed lower energy. Both of continuous 
Table 4 Removed oil \% @ 10, and 25 and 50 wt\% polluted soil using pulsing air flushing @ 3 wt\% surfactant

\begin{tabular}{|c|c|c|c|c|c|c|}
\hline Number & $C_{i}(\mathrm{~g} / \mathrm{kg})$ & $C_{A}(\mathrm{~g} / \mathrm{kg})$ & $C_{f}(\mathrm{~g} / \mathrm{kg})$ & $C_{A}-C_{f}$ & $\left(C_{A}-C_{f}\right) / C_{i}$ & $\frac{\left(C_{A}-C_{f}\right)}{C_{j}} \times 100$ \\
\hline $\begin{array}{l}\text { of air } \\
\text { flushing }\end{array}$ & $\begin{array}{l}\text { Initial } \\
\text { pollutant } \\
\text { concentration } \\
\text { in soil }\end{array}$ & $\begin{array}{l}\text { Final pollutant } \\
\text { concentration in soil } \\
\text { after } 45 \text { min water } \\
\text { washing }\end{array}$ & $\begin{array}{l}\text { Final pollutant concentration } \\
\text { in soil (at the end of the } \\
\text { surfactant treatment) }\end{array}$ & $\begin{array}{l}\text { Different } \\
\text { between } \\
\text { pollutant } \\
\text { concentrations }\end{array}$ & $\begin{array}{l}\text { Different between } \\
\text { pollutant concentrations } \\
\text { over initial concentration }\end{array}$ & $\begin{array}{l}\% \text { of } \\
\text { removed oil }\end{array}$ \\
\hline
\end{tabular}

The percentage of removal of $10 \%$ polluted oil from soil using $3 \%$ surfactant

$\begin{array}{lllllll}\text { First } & 100 & 99.8 & 6.39 & 93.41 & 0.9341 & 93 \\ \text { Second } & 100 & 99.8 & 5.91 & 93.89 & 0.9389 & 94 \\ \text { Third } & 100 & 99.8 & 3.11 & 96.69 & 0.9669 & 97 \\ \text { Fourth } & 100 & 99.8 & 2.16 & 97.64 & 0.9764 & 98 \\ \text { Fifth } & 100 & 99.8 & 1.2 & 98.6 & 0.986 & 99 \\ \text { Sixth } & 100 & 99.8 & 0.49 & 99.31 & 0.9931 & 99 \\ \text { Seventh } & 100 & 99.8 & 0.39 & 99.41 & 0.9941 & 99\end{array}$

The percentage of removal of $25 \%$ polluted oil from soil using $3 \%$ surfactant washing

$\begin{array}{lllllll}\text { First } & 250 & 237.77 & 81.5 & 156.27 & 0.62508 & 63 \\ \text { Second } & 250 & 237.77 & 65 & 172.77 & 0.69108 & 69 \\ \text { Third } & 250 & 237.77 & 45.6 & 192.17 & 0.76868 & 77 \\ \text { Fourth } & 250 & 237.77 & 33.2 & 204.57 & 0.81828 & 82 \\ \text { Fifth } & 250 & 237.77 & 27.8 & 209.97 & 0.83988 & 84 \\ \text { Sixth } & 250 & 237.77 & 22.4 & 215.37 & 0.86148 & 86 \\ \text { Seventh } & 250 & 237.77 & 11 & 226.77 & 0.90708 & 91\end{array}$

The percentage of removal of $50 \%$ polluted oil from soil using $3 \%$ surfactant

\begin{tabular}{lllllll} 
First & 500 & 499.76 & 447 & 52.76 & 0.10552 & 11 \\
Second & 500 & 499.76 & 463 & 36.76 & 0.07352 & 7 \\
Third & 500 & 499.76 & 467 & 32.76 & 0.06552 & 6 \\
Fourth & 500 & 499.76 & 470 & 29.76 & 0.05952 & 7 \\
Fifth & 500 & 499.76 & 466 & 33.76 & 0.06752 & 6 \\
Sixth & 500 & 499.76 & 468 & 31.76 & 0.06352 & 3 \\
Seventh & 500 & 499.76 & 483 & 16.76 & 0.03352 & \\
\hline
\end{tabular}

(direct injection) and pulsed air flushing modes (on/off intervals) were applied to remediation course soil contaminated with 10 wt $\%$ waste lubricant oils in absence and presence of $3 \mathrm{wt} \%$ surfactant concentration. The results found in Tables 2 and 3 shows that both air flushing modes are succeeded to remove the same percentage from pollutant (93 wt\%) at different time 600 and $40 \mathrm{~s}$ for continuous and pulsed air flushing, respectively, this means the performance of using the pulsed air flushing mode over the continuous mode for soil remediation. Therefore, the pulsed air flushing mode was applied with coarse soil contaminated with 25 and $50 \mathrm{wt} \%$ waste lubricant oils in presence of $3 \mathrm{wt} \%$ nonionic surfactant.

Several mechanisms have been postulated to explain why pulsed operation improves contaminant removal by air flushing. Induced surfactant solution flow and surfactant solution mixing might be the two dominating mechanisms.

First, as air is introduced into contaminated soil, air displaces flushing solution in the largest pores and creates temporary flushing solution flow around flushing point [12].When an air-flushing system achieves steady state, preferential airflow pathways consisting of the largest network of pores are formed in the soil, and the induced local flushing solution flow ceases [20]. Pulsing air injection frequently creates non-steady-state conditions and induces flushing solution circulation as the air channels form and collapse during each cycle. The induced flushing solution flow created by the pulsed air flushing substantially enhances the contaminant and oxygen mass transfer in the soil [5]. Second, contaminants in the immediate vicinity of air channels can be removed within few time of the start of flushing, but contaminated present at a greater distance from the air channels is less treated because of the limited mass transport (i.e., diffusion) [8].

The advantage of pulsed over continuous air flushing is that the pulsed can be used with shallow soil contaminated with saturated hydrocarbons. In addition, an optimum pulsing frequency can be determined based on the observed time for the hydrocarbon removal and airflow rate until reach steady state. Yang et al. [24] evaluated the field performance of pulsed air flushing in a short-term pilot test and during long-term system operation. Based on their 
successful results for short-term pilot test, the air flushing system was set to operate long term under pulsed conditions at the selected optimum pulsing frequency. This innovation resulted in higher reduction rates of dissolved benzene, toluene, ethylbenzene, and xylenes (BTEX) than those observed during the continuous operation. Performance monitoring of the air flushing system at 2, 8 , and 12 months of pulsed operation indicated an increase in the hydrocarbon removal rate by a factor of up to three as compared to continuous operation, resulting in cost savings from shorter treatment time and less energy usage.

Master's thesis by Lambert [13], evidence that pulsed air flushing, otherwise known as pulsed bioflushing, is more effective than continuous air flushing because pulsing enhances treatment by inducing groundwater movement and mixing.

The cost of surfactant and air flushing operating mode

One liter commercial grade nonionic surfactant nonylphenol ethoxylate $\left(\mathrm{NPEO}_{9}\right)$ that purchased from Egyptian market is approximately equal $3 \mathrm{US} \$$, and $1,000 \mathrm{ml}$ of $3 \%$ surfactant solution can remediate $100 \mathrm{~kg}$ soil contaminated by $10 \%$ waste lubricant oils. i.e., one tone soil polluted with $10 \%$ hydrocarbons need 30US\$ for complete remediation. Meanwhile, the amount of energy of the compressors used is $1.6 \mathrm{kWh} /$ ton at $220 \mathrm{~V}$ and DC power supplier, where the energy cost is $1 \mathrm{U} \$ /$ ton.

\section{Conclusion}

The removal of poured waste lubricant oils from soil using air flushing with and without surfactant were carried out using laboratory scale model. The effects of surfactant concentrations, water washing cycles and washing time were also studied. The results discussed based on application of surfactant enhancing air-sparging technique as the most suitable and cheapest remedial technology for removal of oil-polluted soil. Reducing the surface tension was found to promote airflow through the preferential air channel. These observations support the use of surfactant to improve air flushing of contaminated zones. This technique, in fact, was found to accelerate the remediation process for NAPL-contaminated soils. Flow time was measured at constant pressure $(2 \mathrm{kPa})$ the evaluated surfactant concentration varied from 3, 5, and $7 \mathrm{wt} \%$, to ensure the micellar solubilization process.

Acknowledgments This work was supported by a grant from Egyptian Petroleum Research Institute, El-Minia University, Faculty of Science, and Geology Department and Engineering Petrotreat Co.
Open Access This article is distributed under the terms of the Creative Commons Attribution License which permits any use, distribution, and reproduction in any medium, provided the original author(s) and the source are credited.

\section{Studied soil reach}

The research work carried out throughout this study at Water laboratory Geology Department, El-Minia University, Faculty of Science, El-Minia- Egypt, and divided into two main parts: the first part is a laboratory study started since April 2009 ending July 2009, in this respect a simulated lab model is designed and packed with artificial polluted soils submerged with nonionic surfactant in presence of air sparging as mentioned in experimental part, where the second part are started in August 2009 ending January 2010 by applying the results of the first part on some rails polluted areas located in El-Minia Government City, the results did not mentioned in this articles, as well as did not published or sending for publication tell now.

\section{References}

1. Cheah PS, Reible D, Valsaraj KT, Constant D, Walsh W, Thibodeaux LJ (1998) Simulation of soil washing with surfactants. J Hazard Mater 59:107-122

2. Chou C-C, Ososkov V, Zhang L, Somasundaran P, (1998) Removal of vonvolatile hydrophobic compounds from artificially and naturally contaminated soils by column flotation. J. Soil Contam 7:559-557

3. Fernandez Perez F, Luque de Castro MD (2000) Micelles training for improvement of continuous subcriticalwater extraction of polycyclic aromatic hydrocarbons in soil prior to high performance liquid chromatography fluorescence detection. J Chromatogr A 902:357-367

4. Gallego JLR, Loredo J, Llamas JF, Va'zquez F, Sa'nchez, (2001) J Biodegradation 12:325-335

5. Heron G, Gierke JS, Faulkner B, Mravik S, Wood L, Enfield CG (2002) Pulsed air sparging in aquifers contaminated with dense nonaqueous phase liquids. Ground Water Monit. Remed. 22(4): $73-82$

6. ITRC (2003) Interstate Technology \& Regulatory Council: Technical and regulatory guidance for surfactant/cosolvent flushing of dnapl source zones. DNAPL-3. www.itrcweb.org/ Documents/DNAPLs-3.pdf

7. Johnson PC, Johnson RL, McWhorter DB, Hinchee RE, Goodman I (1993) An overview of in situ air sparging. Gr Water Monit Remediat 13(4):127-135

8. Johnston CD, Rayner JL, Briegel D (1999) In situ air spargingjust how efficient is it in remediating groundwater contaminated by dissolved petroleum hydrocarbons. In: Proceedings of Contaminated Site Remediation Conference, Fremantle, Western Australia, March, pp 697-704

9. Kim H, Soh HE Annable MD Kim D-J (2004) Surfactantenhanced air sparging in saturated sand. J Environ Sci Tech. 38(4):1170-1175 
10. Kim H, Annable MD, Rao PSC, Cho J (2009) Laboratory evaluation of surfactant-enhanced air sparging for perchloroethene source mass depletion from sand. J Environ Sci Health Part A 44(4):406-413

11. Kommalapati RR (1995) remediation of contaminated soils using a plant-based surfactant, PhD Dissertation, Louisiana State University, Baton Rouge, LA

12. Kueper BH, Frind EO (1988) An overview of immiscible fingering in porous media. J Contam Hydrol 2(2):95-110

13. Lambert J (2008) Pulsed Biosparging of the E10 Gasoline Source in the Borden Aquifer Master's thesis, University of Waterloo, p 164

14. Maqsood I, Huang GH, Huang YF (2004) A groundwater monitoring design through site characterization, numerical simulation and statistical analysis - a North American case study. J Environ Inform 3(1):1-23

15. Marley MC, Hazebrouck DJ, Walsh MT (1992) The application of in situ air sparging as an innovative soil and groundwater remediation technology. Gr Water Monit Remediat

16. Molina-Barahona L, Rodriguez-Va' ZR, Herna' ndez-Velasco M, Vega-Jarquı'n C, Zapata-Pe' rez O, Mendoza-Cantu' A, Albores A (2004) Appl Soil Ecol 27:165-175

17. Mulligan CN, Yong RN, Gibbs BF (2001) Surfactant-enhanced remediation of contaminated soil. A review. Eng Geol $60: 371-380$
18. Reddy KR, Adams JA (1996) In situ air sparging: a new approach for groundwater remediation. Geotech News 14(14):27-32

19. Somasundaran P, Zhang L, Zheng J, Ososkov V, Chou C-C (1997) Removal of nonvolatile hydrophobic compounds from soils by flotation I. Laboratory investigation using a mechanically agitated machine. Adv Environ Res 1:157-165

20. Tomlinson DW, Thomson NR, Johnson RL, Redman JD (2003) Air distribution in the Borden aquifer during in situ air sparging. J Contam Hydrol 67:113-132

21. Urum K Pekdemir T, Çopur M (2003) Process Safety Environ Protect (Solid Waste Manage.) 81(3):203-209

22. Urum K, Pekdemir T, Ross D, Grigson S (2005) Crude oil contaminated soil washing in air sparging assisted stirred tank reactor using biosurfactants. Chemosphere 60:334-343

23. Varadaraj R (1995) Decontamination of hydrocarbon containing substrates (LAW 100). Patent Number 5,417,864, USA

24. Yang X, Beckmann D, Fiorenza S (2005) Field study of pulsed air sparging for remediation of petroleum hydrocarbon contaminated soil and groundwater. J Environ Sci Technol 39(18):7279-7286

25. Zhang L, Somasundaran P, Ososkov V, Chou CC (2001) Flotation of hydrophobic contaminants from soil. J Coll Surf A Phys Chem Eng Aspects 77:235-246 